\title{
Evaluation of Waterlogged Areas in El-Farafra Oasis, Egypt
}

\author{
Ahmed Ibrahim Mohamed, El-Sayed Ewis Omran \\ Soil and Water Department, Faculty of Agriculture, Suez Canal University, Ismailia, Egypt \\ Email: ahmed_shabaka@yahoo.com
}

How to cite this paper: Mohamed, A.I. and Omran, E.-S.E. (2019) Evaluation of Waterlogged Areas in El-Farafra Oasis, Egypt. Open Journal of Soil Science, 9, 232-242. https://doi.org/10.4236/ojss.2019.911014

Received: October 13, 2019

Accepted: November 5, 2019

Published: November 8, 2019

Copyright $\odot 2019$ by author(s) and Scientific Research Publishing Inc. This work is licensed under the Creative Commons Attribution International License (CC BY 4.0).

http://creativecommons.org/licenses/by/4.0/

\begin{abstract}
A geographic information system (GIS) is a system designed to capture, store, manipulate, analyze, manage, and present all types of geographical data. The key word to this technology is Geography-this means that some portion of the data is spatial. In other words, data that is in some way referenced to locations on the earth. The goal of this study is to evaluate how precisely waterlogging can be identified from medium-goals satellite pictures utilizing EWIS list. The point is to distinguish and mapping of the waterlogged territories in the piece of Farafra Desert Oasis of Egypt. To complete this identification, Landsat- 8 symbolism and geographical sheets $(1: 50,000)$ have been utilized and handling through Envi 5.3 and Circular segment GIS 10.3, with field perceptions. The waterlogged regions have positive change $(+)$, anyway grounds have negative change (-). Land has been diminished while water bodies have upward pattern. These waterlogged zones have been mapped at a general exactness of $99.22 \%$. The primary explanations behind this descending rate are mostly improvement and anthropogenic mediations. The investigation shows utility of reconciliation of remote detecting and GIS systems for evaluation of waterlogged territories especially in districts where waterlogging conditions happen both because of over the top water system and poor waste. This investigation is recommended that an appraisal of water logging utilizing remotely detected information ought to be completed at customary interims.
\end{abstract}

\section{Keywords}

Waterlogged, Farafra Desert Oasis, Egypt, Landsat-8, GIS

\section{Introduction}

A geographic information system (GIS) is a framework for gathering, managing, 
and analyzing data. Rooted in the science of geography, GIS integrates many types of data. It analyzes spatial location and organizes layers of information into visualizations using maps and 3D scenes. With this unique capability, GIS reveals deeper insights into data, such as patterns, relationships, and situationshelping users make smarter decisions [1].

Land corruption in the Farafra Desert Oasis is anticipated to turn into a genuine and broad natural issue in the following couple of years because of a miss land use arranging. The principle sorts of land debasement in the Farafra Desert Oasis are waterlogging and soil salinization. Farafra Desert Oasis faces genuine water table issues brought about by over-water system and hard skillet at different profundities [1]. It is less difficult to anticipate antagonistic impacts on wetlands if toward the beginning of the arranging stage the land being referred to is recognized as a wetland. A wetland is a zone whose dirt is either persistently or occasionally soaked with dampness. Wetlands are transitional terrains among earthbound and sea-going frameworks where the water table is ordinarily situated on or close to the surface or where the ground is secured by shallow water. Such districts may likewise be halfway or altogether secured by shallow water pools. Without fitting waste frameworks, new water system activities have been brought into the bowl. The permeation from water system zones has caused serious land corruption issues. Executing water system ventures without fitting seepage framework has interfered with the harmony between groundwater energize and discharge bringing about gradual additions to the El-Farafra groundwater table. The area is confronting the water logging issue emerging from existing over water systems and hardpans. In case of deficient seepage, the profundity of the water table will decrease after some time and a shallow saline water table will likely develop and some irrigable land will be relinquished in the long run [2]. Within the sight of a shallow saline water table, the advancement of harvests can endure if salts collect in the dirt by fine activity and additionally straightforwardly as an outcome of waterlogging [3]. Waterlogged soils are developed and harming farmland and rich soils.

A few analysts recognized these issues [1] and [4], and their goal was to characterize proper methods to overview, group, oversee and use these unusual soils [5]. Such nourishment security advancement needs exact land and water information to verify basic leadership forms for interest in the area: An interesting normal for RS systems is the capacity to record enormous scale data in a brief timeframe [6] [7] [8]. The developing improvement of rural fields and the broad waterlogging and salinization requests opportune and dependable checking and perception (remote detecting) framework fundamentally for chronicle changes and envisioning further debasement. Therefore, reasonable and opportune choices can be taken to change the board rehearses or to take appropriate medicinal activities [9]. Satellite-determined remote detecting uses space-borne sensor stages to measure the reflectance or discharges of electromagnetic radiation from the Earth [10]. Otherworldly properties of various land surfaces related to 
particular water and soil types and their gatherings (e.g., [11] may give methods for rapidly and remotely recognizing and outlining waterlogged zones.

The principle goal of this study is to research a legitimate and conceivable model for observing, mapping, and foreseeing the waterlogged zones in the Farafra Desert Oasis, Egypt by utilizing Landsat- 8 satellite pictures.

\section{Materials and Methods}

\subsection{Study Area}

The downturn of Farafra Desert Oasis is situated in the center piece of the Western Desert about $650 \mathrm{~km}$ toward the southwest of Cairo. El-Farafra discouragement is the second biggest sorrow in the Western Desert of Egypt. It lies basically between longitudinal $27^{\circ} 20^{\prime} \mathrm{E}$ and $29^{\circ} 00^{\prime} \mathrm{E}$, and scope $26^{\circ} 28^{\prime} \mathrm{N}$ and $27^{\circ} 40^{\prime} \mathrm{N}$. The examination zone is a piece of the Farafra Desert Oasis, and it is situated toward the south of Farafra Desert Oasis, New Valley Governorate. The limestone level of the center scopes of Egypt stretches out along the two sides of the Nile. It shapes an unpleasant going, almost level upland desert surface meagerly veneered by a disintegration asphalt made up of alluvium and rock. The incomparable Desert Oasis of Dakhla and Kharga lie in the shadow of the southern edge of this limestone level [12], toward the north untruth the sorrows of Farafra and Bahariya Desert Oasis. The Farafra has an unpredictably triangular shape and limited by soak precipices on three sides.

The dirt temperature arrangement of the locale could be portrayed as hyperthermic and torric soil dampness. The investigation territory is portrayed by sweltering dry desert atmosphere; month to month temperature esteems infer a comparative dissemination of most extreme, least and mean temperature esteems during the year, a normal of $23.3^{\circ} \mathrm{C}$ and a normal of roughly $30.8^{\circ} \mathrm{C}$ in summer and $14.2^{\circ} \mathrm{C}$ in winter. The most extreme mean temperature was estimated in June at $40.0^{\circ} \mathrm{C}$, while in January the base temperature was recorded at $5.0^{\circ} \mathrm{C}$. The precipitation esteems around $0.63 \mathrm{~mm} / \mathrm{month}$ are incredibly little throughout the year. Qualities ran from 3.7 to $13.18 \mathrm{~mm} /$ day for evapotranspiration. Wind paces contrast from 18 to $24 \mathrm{~km} / \mathrm{h}$ with transcendent headings for N - S and NW - SE.

The Farafra despondency is an unpredictably formed semi-shut bowl where it is encompassed by north, south and west ledges. The downturn ground bit by bit increments toward the south and streams into the level framing the southern slope of Dakhla and Abu Minqar Desert Oasis (Figure 1). The downturn is for the most part underlain by Palaeocene-Eocene sedimentary rocks, where the chalk of Upper Cretaceous (Khoman Development) and Palaeocene (Tarawan Arrangement) covers huge zones in the north, and the shale (Dakhla Development) is predominantly uncovered in the south. Lower Eocene developments (El-Naqb and Farafra limestone) top conspicuous ledges [13]. The examination region has a place basically with Pleistocene silt. The outside of the region is basically involved by Upper Cretaceous Nubian Developments made up of 


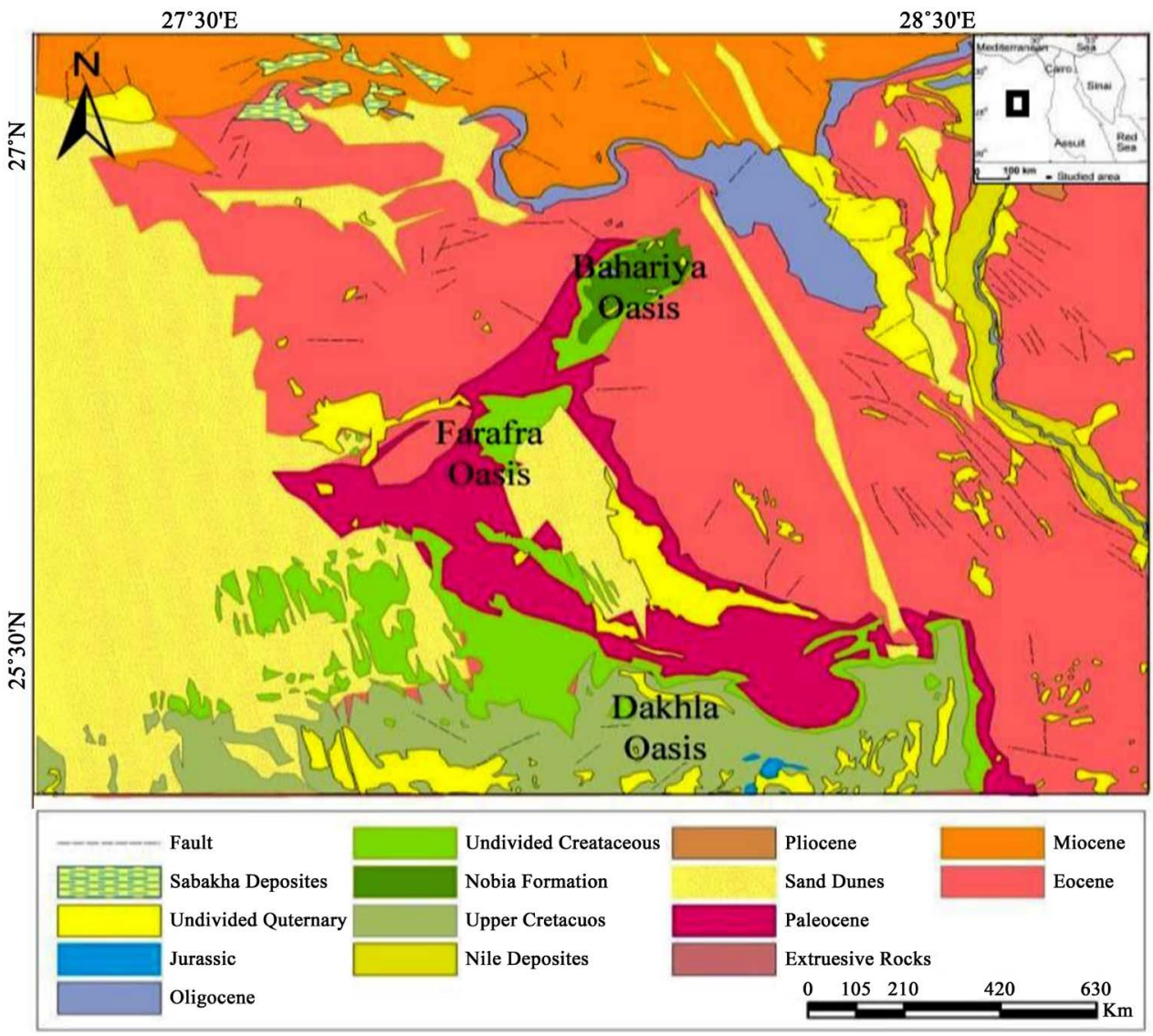

Figure 1. Geological map of the Farafra Oasis based on the Geological map of Egypt [16] [17].

cross-had relations with sandstones with between slept with shale. The extrusive rocks, which have a place with the Precambrian age, are uncovered in dissipated patches. On the limestone level, Tertiary Eocene, and Paleocene limestone and shale overlie the Nubian Arrangement, which is privately interfered by basalts accepted to be recently Tertiary or Early Pleistocene age [14].

Sand rises spread the eastern bit of the Farafra OasisThese ridges for the most part stretch out toward the southern slope of Dakhla discouragement for around $200 \mathrm{~km}$ from the upper east corner of the downturn. Interdune districts become more extensive toward the south and east, and the decrease in sand supply in this way destroys the generally isolated rise edges into particular barchans before arriving at the Dakhla melancholy scarves [15]. Sand sheets additionally spread huge surface territories in different areas and have in this way clouded the greater part of the fluvial channels made at wetter climatic stages.

\subsection{Geomorphologically}

It is described by certain prominent geomorphic units, to be specific; plateaux, barren wasteland and wretchedness floor, where the last is isolated into the accompanying sub-geomorphic units (Figure 2); white plain, out-wash plain, Aeolian aggregations (sand sheets and sand rises), playas, El-Hattias, sabkhas, alluvial fans, dry Channels, mud pads, foot-slope slants and undifferentiated buildings. 


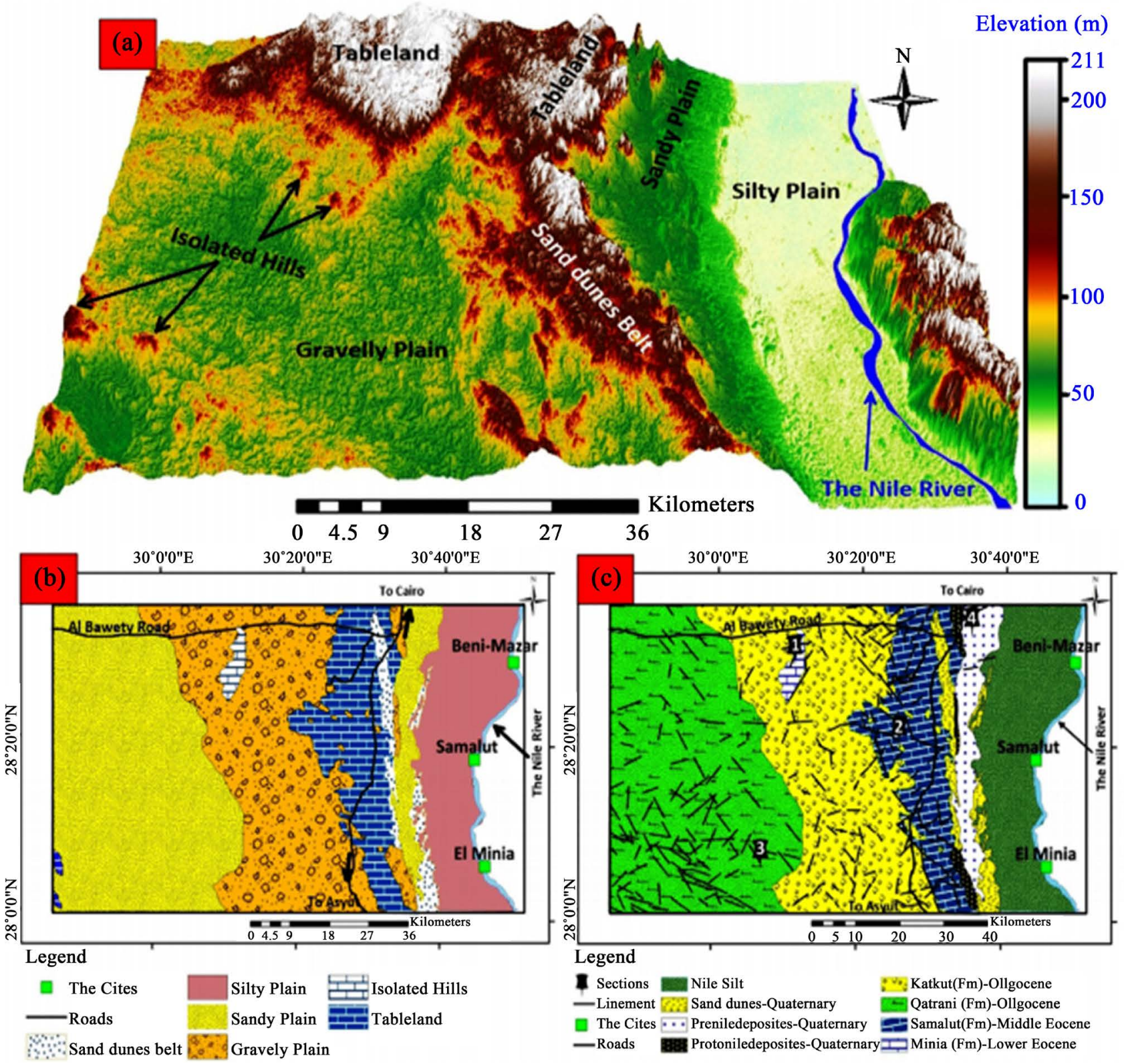

Figure 2. Geomorphological and geological setting of the study area. (a) Three-dimension view showing the main landform of the study area; (b) Geomorphology map of the study area; (c) Geology map of the study area [16].

El-Shazly [18] and [13] inferred that the geomorphologic highlights showed in the contemplated zone incorporate: slopes, edges, lacustrine stores, neighborhood swamps, crescentic sand rises, and sand sheets.

[19] referenced that running water and fluviatile disintegration played out a significant job in the emptying of Kharga Desert Oasis and different sorrows of western desert, essentially in the early times of their development. Started by fluvial activity, the exhuming of western desert despondencies was done by aeolian activity. The consequences of mineralogical examinations uncovered that smectites are the dominating mud mineral pursued by kaolinite, between stratified minerals, vermiculite, hydrous mica, chlorite and palygorskite in a dimi- 
nishing request with the exception of in the foot-slope slants where kaolinite is the prevalent.

The presence of incalculable measures of dirt minerals demonstrate that El-Farafra wretchedness soils have been exposed to water activity for quite a while during either their arrangement or transport from the source area. Besides, the varieties in the earth mineral collections mirror the multi-inception nature as well as variety of multi-depositional. Some shale-inferred soils in New Valley governorate (El-Kharga Desert Oasis, El Dakhla Desert Oasis, El-Zaiyat plain and Gharb El-Mawhub) were contemplated by [20]. The data obtained demonstrated that in Gharb El-Mawhub, the surface class of the ground tests examined contrasts from sandy topsoil, residue soil and dirt with a better surface and a coarser one in El-Kharga and El-Zaiyat. The greater part of these dirts in many areas is decent to exceptionally saline with low calcium carbonate.

\subsection{Data and Methods}

The quick soil disintegration brought about by waterlogging and salinization spreading is distinguished in two stages and assessed utilizing the accompanying philosophy. The initial step comprises of Landsat- 8 satellite pictures procured in the years 2016, which were gotten and prepared to screen the waterlogged territory utilizing EWIS record [21]. The distinguishing proof of waterlogging and soil salinization can be accomplished utilizing either visual understanding or advanced investigations of uncovered and developed soil and vegetation list [21], [6] and [8]. Similarly, these various strategies require ground truthing and field confirmation.

\subsection{Methodology}

To set up the information satellite pictures for further preparing, the accompanying pre-handling steps were performed: radiometric alignment, barometrical amendment, co-enrollment, and resampling. Radiometric alignment and environmental remedy were directed by [22]. The acquired pictures were changed over to at-satellite brilliance utilizing the Landsat- 8 adjustment apparatus in ENVI 5.3. From that point forward, each picture was changed over to at-satellite reflectance. The necessary data including the information procurement date and sunrise were acquired from the Landsat header records. The FLAASH technique was utilized to change over at-satellite reflectance to surface reflectance for full total redress.

\subsection{Waterlogged Area Extraction Techniques}

In areas where overcast spread or vegetation coverings don't confine water body recognition, optical remote detecting techniques are successful for evaluating examples of immersion [23]. In view of the solid retention of close infrared (NIR) radiation by water, water bodies can be mapped by thresholding of NIR reflectance alone and utilizing proportions or standardized proportions of ref- 
lectance among NIR and red, green, short-wave infrared, or center infrared groups.The element extraction strategy was utilized to show the spatiotemporal changes of waterlogged territory for the Farafra Desert Oasis in the period from April 2016 to December 2016 and from Sep 2014 to Sep 2018 utilizing Landsat- 8 pictures. To accomplish this, the chosen records were determined dependent on [21], examined and arranged autonomously (utilizing explicit edges) to extricate the waterlogged territory in each picture. EWIS phantom records [21] were utilized for separating waterlogged zones in Farafra Desert Oasis. This file separated the waterlogged regions (edited territories immersed with water). So as to identify the waterlogged region changes, the waterlogged in each picture was removed independently. In doing as such, five phantom groups of Landsat- 8 were utilized to build the complexity among water and other dim surfaces. The essential point was to boost distinguishableness of water and non-water pixels through band differencing. In like manner, condition (1) [21] was utilized to successfully stifle non-water pixels and concentrate surface water with improved exactness. The coefficients utilized in Condition (1) are the number-crunching blends of the picked phantom groups, which were resolved, in light of basic assessment of the reflectance properties of different water types. Numerous iterative procedures were applied to recognize parameters that boost the detachability of water and non-water surfaces described by low reflectance.

$$
\text { EWIS }=(\mathrm{b} 2-\mathrm{b} 4-\mathrm{b} 7)-(\mathrm{b} 5+\mathrm{b} 7)=(\text { Blue }- \text { Red }- \text { SWIR })-(\text { NIR+SWIR })
$$

Similar to NDVI, EWIS produces -1 to +1 value. However, most of the water bodies are found near to +1 value. EWIS values between +0.4 to +0.9 were classified for the images as waterlogged areas.

\section{Results}

\subsection{EWIS Record for Waterlogged Recognizable Proof}

Spatial conveyance of waterlogged zones at El-Frafra Desert Oasis appears in Figure 3. To distinguish the progressions that have been happened yearly, Figure 3

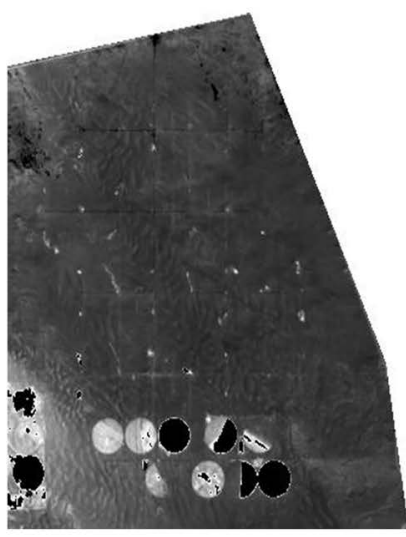

$21 / 9 / 2014$

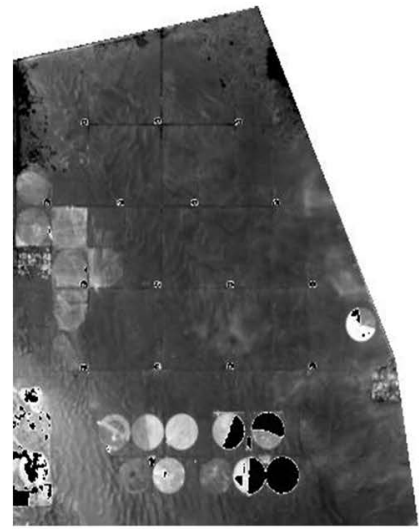

$24 / 9 / 2015$

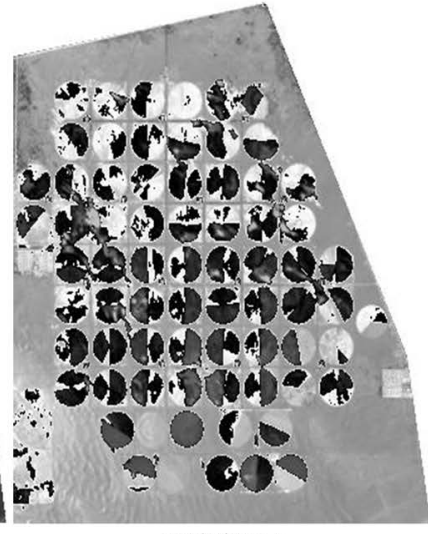

$26 / 9 / 2016$

Figure 3. Identified waterlogged areas at El-Frafra using EWIS index from Sep 2014 to Sep 2016. 
demonstrates the recognized waterlogged (white) zones from Sep 2014 to Sep 2016. The waterlogged territory (Figure 3) was grouped under two classifications one where there was clear surface ponding as "waterlogged zone" and other where there was high dampness content as "zone delicate to water logging". The waterlogged region was clear in dim blue to somewhat blue dark tone during pre storm and in pale blue dark to light pale blue tone during post rainstorm, though the region touchy to waterlogging showed up in light dim to dim grayish tone during pre storm and light to dim caramel dim tone during post storm season.

Figure 4 demonstrates the estimation of the NDVI record, which can extend from -1.0 to 1.0 for El-Frafra. The negative NDVI qualities are for the most part because of mists and water. The estimations of NDVI near zero are chiefly because of rocks and exposed soil. NDVI qualities running from 0 to 0.1 compare to sand or purge zones of rocks. NDVI qualities extending from 0.2 to 0.3 speak to bushes and knolls, and NDVI qualities running from 0.6 to 0.8 demonstrate tropical and mild backwoods.

\subsection{Waterlogged Change Detection}

Post arrangement examination of progress identification technique was utilized to deliver a nitty gritty change data of water and horticulture grouped pictures. In this stage, the characterized pictures were overlaid so as to get the progressions of water and farming. Point by point changes data of waterlogged and non-water zone characterized pictures (Figure 5 and Table 1) were delivered.

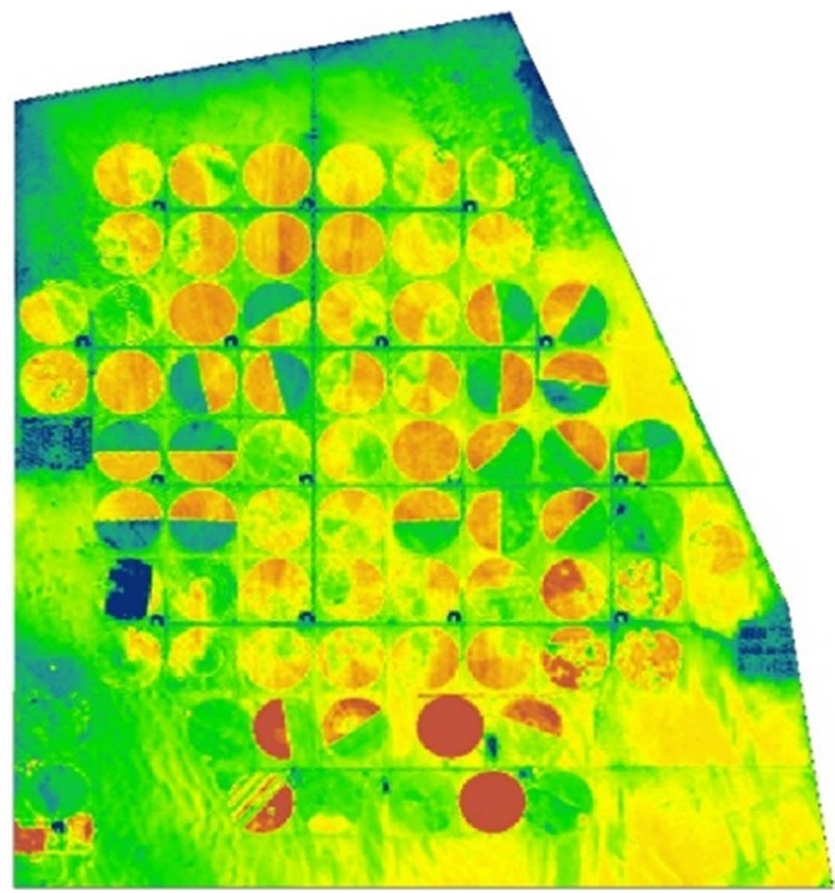

Figure 4. NDVI for El-Frafra, Sep 2018. 


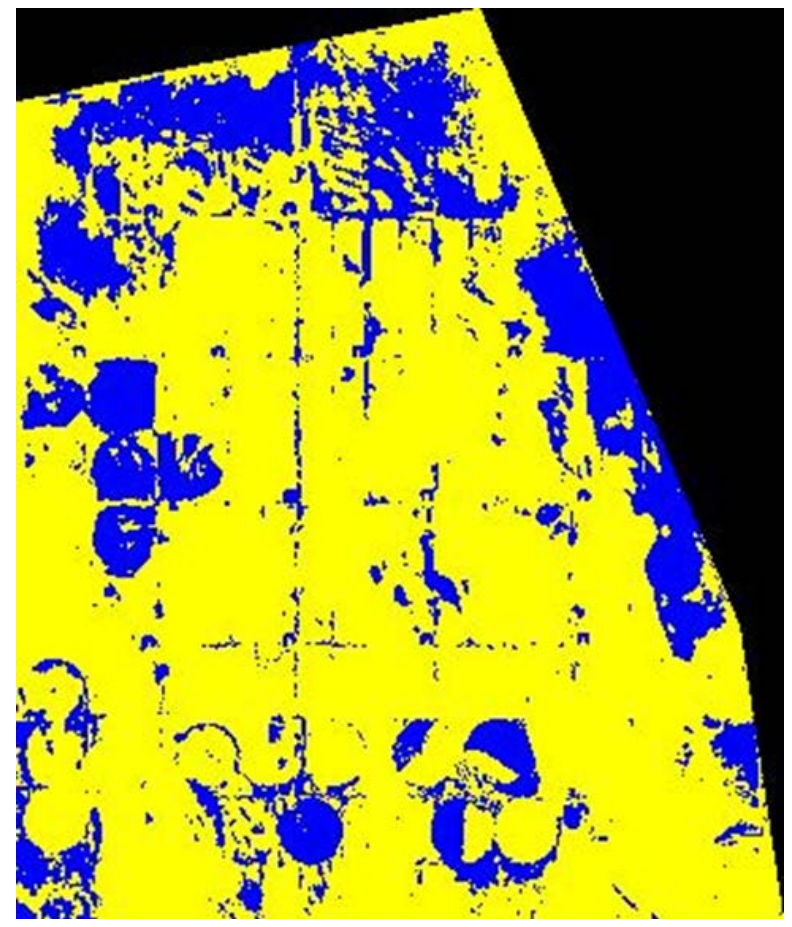

Figure 5. Change maps of waterlogged area and non-water through the year 2015-2016.

Table 1. The confusion matrix results of EWIS.

\begin{tabular}{ccccc}
\hline Classes & $\begin{array}{c}\text { Producer Accuracy } \\
(\%)\end{array}$ & $\begin{array}{c}\text { User's Accuracy } \\
(\%)\end{array}$ & $\begin{array}{c}\text { Commission } \\
(\%)\end{array}$ & $\begin{array}{c}\text { Omission } \\
(\%)\end{array}$ \\
\hline Waterlogged & 99.40 & 100.00 & 0.00 & 0.60 \\
Non-Water & 100.00 & 99.59 & 0.50 & 0.00 \\
Overall Accuracy \% & & 99.22 & & \\
Kappa Coefficient & & 0.987 & & \\
\hline
\end{tabular}

\section{Conclusions}

The goal was to early portray the waterlogged regions utilizing Landsat- 8 information. Landsat- 8 symbolisms are demonstrated to be helpful information to distinguish waterlogged regions in this examination. Utilizing medium goals latent information, separating waterlogged territory can be reasonable. Radiometric lists have their very own mark highlights and qualities for recognizing the objectives among various otherworldly groups. The EWIS was evaluated in the ebb and flow concentrate to depict precisely waterlogged territories and improve its essence in remotely detected symbolism. The investigation has demonstrated that a quick and dependable evaluation of the waterlogged and touchy territories of water logging can be made by the EWIS list.

The surface waterlogged regions were outlined from LandSat- 8 satellite symbolism utilizing EWIS file strategy. The outcome shows that a waterlogged zone ranges from zero to +1 . The positive qualities +1 mean the event of waterlogged zones though the negative qualities -1 is for vegetation spread. An expansion in 
waterlogged zone is watched. The outcomes demonstrated an exceptional expanding pattern in the waterlogged territory in couple of months. On the off chance that such an expanding pattern in Farafra Desert Oasis waterlogged proceeds, the land will lose its whole surface in not so distant future or in others words the surface land will be for all time changed over into waterlogged region.

\section{Conflicts of Interest}

The authors declare no conflicts of interest regarding the publication of this paper.

\section{References}

[1] El Bastawesy, M., Ramadan, A.R., Faid, A. and El Osta, M. (2013 ) Assessment of Waterlogging in Agricultural Mega Projects in the Closed Drainage Basins of the Western Desert of Egypt. Hydrology and Earth System Sciences, 17, 1493-1501. https://doi.org/10.5194/hess-17-1493-2013

[2] Datta, K.K. and Jong, C.D. (2002) Adverse Effect of Waterlogging and Soil Salinity on Crop and Land Productivity in Northwest Region of Haryana, India. Agricultural Water Management, 57, 223-238. https://doi.org/10.1016/S0378-3774(02)00058-6

[3] Houk, E., Frasier, M. and Schuck, E. (2006) The Agricultural Impacts of Irrigation Induced Waterlogging and Soil Salinity in the Arkansas Basin. Agricultural Water Management, 85, 175-183. https://doi.org/10.1016/j.agwat.2006.04.007

[4] Omran, E.S.E. (2012) A Neural Network Model for Mapping and Predicting Unconventional Soils at a Regional Level. Applied Remote Sensing Journal, 2, 35-44.

[5] Omran, E.S.E. (2008) Is Soil Science Dead and Buried? Future Image in the World of 10 Billion People. Catrina, 3, 59-68.

[6] Omran, E.S.E. (2017a) Early Sensing of Peanut Leaf Spot Using Spectroscopy and Thermal Imaging. Archives of Agronomy and Soil Science, 63, 883-896. https://doi.org/10.1080/03650340.2016.1247952

[7] Omran, E.S.E. (2017) Early Waterlogged Identification System to Assess Spatiotemporal Impact of the New Suez Canal, Egypt. Journal of Coastal Conservation, 21, 1-17. https://doi.org/10.1007/s11852-017-0546-0

[8] Omran, E.S.E. (2018) Remote Estimation of Vegetation Parameters Using Narrowband Sensor for Precision Agriculture in Arid Environment Egypt. Journal of Soil Science, 58, 73-92. https://doi.org/10.21608/ejss.2018.5614

[9] Masoud, A.A. and Koike, K. (2006) Arid Land Salinization Detected by Remotely-Sensed Landcover Changes: A Case Study in the Siwa Region, NW Egypt. Journal of Arid Environments, 66, 151-167. https://doi.org/10.1016/j.jaridenv.2005.10.011

[10] Lillesand, T. and Kiefer, R. (2008) Remote Sensing and Image Interpretation. 6th Edition, John Wiley \& Sons, Hoboken.

[11] Ben-Dor, E. (2002) Quantitative Remote Sensing of Soil Properties. Advanced Agronomy, 75, 173-243. https://doi.org/10.1016/S0065-2113(02)75005-0

[12] Said, R. (2017) The Geology of Egypt. CRC Press, Boca Raton. https://doi.org/10.1201/9780203736678

[13] El-Azabi, M. and El-Araby, A. (2000) Depositional Cycles: An Approach to the Sequence Stratigraphy of the Dakhla Formation, West Dakhla Farafra Stretch, Western Desert, Egypt. Journal of African Earth Sciences, 30, 971-996. https://doi.org/10.1016/S0899-5362(00)00064-6 
[14] UNDP/UNESCO (2001) Joint Project for the Capacity Building of the Egyptian Geology Survey and Mining Authority and the National Authority for Remote Sensing Space Science for the Sustainable Development of the South Valley and Sinai.

[15] Embabi, N.S. (2004) The Geomorphology of Egypt. Landform and Evolution: The Nile Valley and Western Desert. The Egyptian Geographical Society, Special Pub., Cairo, Vol. 1.

[16] Egyptian General Petroleum Company (EGPC) (1987) Geological Map of Egypt. NG 35 NE Farafra, Conoco Coral. Scale: 1:500000.

[17] Hermina, M. (1990) The Surroundings of Kharga, Dakhla and Farafra Oases. In: Said, R., Ed., The Geology of Egypt, Balkema/Rotterdam/Brookfield, 734 p.

[18] EL-Shazly, E. (1976) Geology and Ground Water Potential of Kharga and Dakhla Oases Area, Western Desert, Egypt from NASA Landsat-1 Satellite Images. Academy of Scientific Research, Cairo.

[19] Abu Al-Izz, M.S. (1971) Land Forms of Egypt. The American University in Cairo press, Dar Al Maaref, Cairo.

[20] El-Aziz, S., Khalifa, E., Ghallab, A. and Selmy, S. (2005) Mineralogical Composition of Some Shalederived Soils in the New Valley. Assiut Journal of Agricultural Sciences, 36, 61.

[21] Omran, E.S.E. (2016a) Early Warning Information System for Land Degradation Hazards in New Suez Canal Region, Egypt. Modeling Earth Systems and Environment, 2, 1-13. https://doi.org/10.1007/s40808-016-0148-0

[22] Schroeder, T.A., Cohen, W.B., Song, C., Canty, M.J. and Yang, Z. (2006) Radiometric Correction of Multi-Temporal Landsat Data for Characterization of Early Successional Forest Patterns in Western Oregon. Remote Sensing of Environment, 103, 16-26. https://doi.org/10.1016/j.rse.2006.03.008

[23] Ward, D.P., Hamilton, S.K., Jardine, T.D., Pettit, N.E., Tews, E.K., Olley, J.M., et al. (2013) Assessing the Seasonal Dynamics of Inundation, Turbidity, and Aquatic Vegetation in the Australian Wet-Dry Tropics Using Optical Remote Sensing. Ecohydrology, 6, 312-323. https://doi.org/10.1002/eco.1270 